\title{
The Research of "Split Classroom"Teaching Mode in Chemistry and Physiology Experiment Teaching
}

\author{
Zhang Jin ${ }^{1}$, WangMeng ${ }^{1}$, Lin $\mathrm{Na}^{1}$, Du Hang ${ }^{1}$
}

\author{
${ }^{1}$ Binzhou Polytechnic, Binzhou, Shandong 256600, China \\ Email:_zhangjinbz@163.com
}

\begin{abstract}
Physiology is an experimental science, all of its knowledge comes from clinical practice and experimental research. In the teaching of physiology, in addition to theoretical teaching, the key chapters and key contents will be set with corresponding experimental contents to deepen students' understanding of theoretical knowledge and teach students some basic experimental skills, which can also lay the foundation for students' future knowledge reserve, professional ability and quality training. As a new teaching mode, split class provides a new way for teachers to reform physiology teaching. Based on the practice of implementing the split class in the experimental teaching of science for Tibetan ethnic college students, this paper summarizes the relevant experience to ensure the effective implementation of the split class, so that students can really learn something in the experiment, have their own advantages and use their knowledge. In the long run, students' quality and ability will be greatly improved.
\end{abstract}

Keywords: split classroom, physiology, experiment teaching

\section{INTRODUCTION}

Physiology is a professional compulsory course for medical college students. Its main task is to clarify the laws and mechanisms of various normal functional activities of the body and its components, the effects of changes in the internal and external environment on these functional activities, and the corresponding adjustments made by the body to adapt to environmental changes and maintain the overall life activities. Physiology is an experimental science, its development is inseparable from clinical practice and experimental research. Therefore, in the teaching of physiology, in addition to the theoretical teaching, the corresponding experimental contents will be set for the key chapters and key contents. Although the interaction between teachers and students is advocated in the experimental teaching at the present stage, the experimental teaching mode is relatively single, and the teacher's explanation and infusion are still the dominant, so the quality and ability of students have not been improved in essence [3-4]. Under the background of deepening the reform of teaching mode, Professor Zhang Xuexin of Fudan University has put forward a new teaching mode of "split classroom", which has been practiced and explored in various courses in many schools, and the effect is remarkable [5-6]. Based on the actual situation of our school, we discussed the application of "split class" mode in physiology experiment teaching.

\subsection{Related Work}

.Physiological experiment is a very important part of physiology teaching, and it is a basic required course for clinical medicine, nursing, medical laboratory technology and other medical majors. Physiological experiments include the guidance and determination of action potential of neural stem, the influence of factors on arterial blood pressure of rabbits, the regulation of respiratory movement, and the influence of urine generation. The main purpose is to make students master the basic operation and basic skills of physiological experiments through learning and practice[1]. According to the experimental teaching and practice process, it can consolidate and deepen students' understanding of relevant theoretical knowledge, improve students' ability to find and analyze problems, cultivate students' team cooperation ability, and lay the foundation for future clinical work. But in the process of experimental teaching, we found that there are still the following problems.Solidification of experimental teaching mode at present, most teachers still use the traditional teaching mode for the experimental course teaching, often ignoring the dominant position of students, students are in a passive learning state, students have no room to play in the classroom, they can only accept knowledge indoctrination. The mechanical cramming education mode can not make students' ability to be trained in all aspects, and the traditional teaching mode can not meet the needs of 
all-round education at this stage[2]. The teaching mode of physiology experiment course is still the traditional mode. Students are required to preview the experiment before class, and the teacher explains the purpose and principle of the experiment in class[1]. Then the teacher demonstrates the experiment operation, and the students complete the experiment in groups and submit the experiment report. The whole process of the experiment is just a duplication of the process of teaching, students often do not have a more in-depth thinking and exploration of the problems encountered in the experiment[3]. If it goes on like this, the students' innovative quality and ability can not be cultivated and improved, and the experimental course will lose its real significance.

\subsection{Our Contribution}

Differences in learning situation lead to great differences in teaching effect. Our university is a university for nationalities, and students are mainly from Tibet Autonomous Region and the mainland. Influenced by language and culture, the students in the district are weak in learning foundation and lack of learning initiative. They often follow blindly in the process of experiment. They rely too much on the teachers' teaching and help and the students with strong leadership in the group, and lack of their own thinking and judgment. Although they have studied in the experimental class, their abilities of hands-on operation and team cooperation are not improved much.According to the class situation of physiological experiment course in the past, the performance of students in a class is different. Some students are active in learning and can lead the whole group to complete the experiment operation. They have active thinking and strong hands-on ability[7]. The understanding and grasp of the experimental content often become the direct reason for the quality of the experimental results. Some students study passively in order to get the experimental results, they often just complete the experiment step by step, without too much requirements for the experimental results, and lack the ability of active thinking. There are also some students who have weak learning foundation and low requirements for themselves. They often act as bystanders in the process of experiment. They do not participate in the experiment or directly, just wait for the results to complete the experiment report. The effect of pre class preview is not good. Students do not form a good habit of pre class preview. The preview of experimental content often just takes the experimental teaching material to browse the experimental project in a hurry, and does not have in-depth study on the purpose and principle of the experiment. In the process of classroom teaching, although the teacher will explain the purpose and principle of the experiment, due to the limited time in class, the time for students to think and understand is relatively short. The purpose of experiment preview is to make students familiar with the experiment operation, but more importantly, let students understand the experiment principle and design, with problems, through hands-on operation, to solve problems, in-depth grasp of theoretical knowledge. In the real experimental class, many students will only complete the experimental project step by step, and do not care about the principle behind the operation steps. What's more, according to the operation steps in the teacher's courseware or teaching materials, they have to take a look at the steps and do one-step experiments. They have no overall control and understanding of the whole process of the experiment, and can not achieve the real purpose of experimental teaching.

\section{BACKGROUND}

The evaluation standard of experimental course is relatively single, and most physiological experimental courses belong to examination courses. Summative evaluation method is adopted, that is, the assessment of experiments is often based on the experimental report submitted by students, so students' understanding of experimental course assessment still stays in submitting an experimental report that meets the requirements of teachers[8].Of course, students who are active in learning and love experimental courses can always get better evaluation, because they can always seriously complete the writing of the report, and the discussion and analysis of the experimental results are also very detailed. But some opportunistic students often lack thinking, and even copy the reports of the same group, which makes a single evaluation method unable to evaluate students objectively and comprehensively, This is obviously not consistent with our original intention of setting up physiological experiment course."Bisection classroom" is a new mode of classroom reform proposed by Professor Zhang Xuexin of Fudan University Based on the current situation of domestic university classroom and the law of psychology. In form, it divides the class time into two parts, half for teachers and half for students to discuss; The discussion is preceded by an internalization process, so that the students can understand and absorb the content taught by the teacher, and then participate in the discussion in a prepared way. Because of its clear separation of teaching into three processes in terms of time, presentation, assimilation and discussion, "split class" is also referred to as pad class [9].The innovation of "split class" is to stagger the two forms of teacher's teaching and student's discussion in time, so as to leave students time for autonomous learning and carry out individualized internalization and absorption through autonomous learning. At the same time, "split class" emphasizes the process evaluation in the assessment method, 
and pays attention to the learning needs of different students, so that students can determine the degree of investment in the course according to their personal learning goals.

\section{CONCLUSION}

In the second semester of 2017-2018 academic year, the "split classroom" teaching mode was adopted in the physiological experiment teaching of freshmen majoring in nursing. Determine the overall goal of the experiment. Before each experiment, teachers need to do a good job in teaching design, and determine the overall goal of the experiment from three aspects of theoretical level, operation skills and quality improvement. Taking the regulation of cardiovascular activity in rabbits as an example, the following teaching objectives were determined: theoretical aspect: To observe the influence of nerve and humoral factors on arterial blood pressure in rabbits, and to deepen students' understanding of the formation mechanism of arterial blood pressure, influencing factors and the regulation mechanism of cardiovascular activity. Ability: master the operation of rabbit neck, arterial intubation technology. Quality: cultivate students' practical ability, comprehensive practical ability and team cooperation ability to lay the foundation for future study and work.

There were 26 students in class 1 , including 16 from outside Tibet and 10 from inside Tibet. According to the grouping requirements of Tibetan Chinese mixture and men and women matching, every four people are a group, and the leader is elected .Classroom form: the form of "split class" is more flexible. According to the content and characteristics of each experiment and with reference to the class arrangement, the experimental principle can be selected for split, a certain experimental operation process can be split, and the later experimental results and discussions can be split. Taking the neurohumoral regulation of cardiovascular activity in Experiment 4 as an example, in this experiment, we adopted the split mode in class. The purpose and principle of the experiment were taught by teachers. The students in the middle operation were divided into groups. Then the experimental results were discussed in groups. After the discussion, the students were randomly selected, Finally, the teacher makes a summary according to the students' speech. Assessment criteria: after the split classroom teaching, the assessment of the experimental course includes two parts[7].Experimental report assessment: in addition to the traditional experimental report mode, the column "Liang kaobang" is added in the experimental discussion column. Shining: ask students to write the biggest personal gains in this experiment; Test you: ask the students to write down the problems that they have understood after the experiment, but other students may not; Help me: ask the students to write down the questions they still don't understand after the experiment. At the same time, students are encouraged to write their own unique opinions and thinking experiences in this experiment for mutual exchange. According to the common problems of "help me", we will discuss and answer them. Process assessment: process assessment is introduced into the experimental course to carry out mutual assessment within and between groups, select excellent groups and excellent members, and require students to give evaluation reasons in the stage of mutual assessment, so as to ensure fairness and justice. The final assessment result consists of two parts: the experimental report result and the process assessment result.

Students have a more thorough understanding of the experimental principle and operation. Students can combine the experimental phenomenon with the principle through discussion, and understand the principle according to the phenomenon. In the discussion stage, students not only think and analyze the experimental results, but also sort out and analyze the problems encountered in the experimental operation, and correct the wrong operation. Students are well prepared and able to discuss effectively, which greatly improves the efficiency of the classroom It improves the students' learning initiative. After the implementation of bisection, the author introduces the process evaluation into the curriculum evaluation system, which greatly improves the students' participation, and $50 \%$ of the experimental results come from the inter group evaluation and intra group evaluation. Students can take the experiment seriously, cooperate with each other in the experimental process, and the atmosphere is harmonious, which not only improves the correctness of the experiment, but also improves the cohesion among students.help to train students' independent thinking. After learning the neurohumoral regulation of cardiovascular activities in Experiment some students proposed that the effect of stimulating vagus nerve and decompressing nerve on blood pressure was significant and rapid, while the effect was slow after injection of epinephrine and norepinephrine. Therefore, the characteristics of neurohumoral regulation and neurohumoral regulation were related, and the experimental phenomenon was explained by the characteristics of neurohumoral regulation It enhances the students' language organization and expression ability. In the process of discussion, the members of each group actively speak, and often have a heated discussion when they encounter differences. After the discussion, the teachers will spot check the discussion. Students from fear of speaking to active request to speak, cultivate students' self-confidence, at the same time, students' language organization and expression ability is also improved. concluding remarks, "divided classroom" as a new classroom teaching mode preserves the traditional essence of 
teachers' explanation to the greatest extent, and increases the links of students' discussion, and effectively stimulates students' initiative in learning. Especially after experiencing the traditional teaching in middle school, college students are tired of the traditional teaching mode. If we always adopt the traditional rigid experimental teaching mode, students will feel nothing new and tired. We apply the concept of "split class" to the physiological experiment teaching, which solves the problems in the current physiological experiment teaching, and improves the students' comprehensive quality and ability[9]. Although in the process of implementation, teachers are required to innovate the classroom design and increase students' learning tasks, which is hard to accept for some students who do not study seriously at ordinary times and do not participate in the experimental class. As long as teachers are willing to take the time to design the classroom organization form carefully, the classroom will become lively and fun, so that students can really learn from the experiment, In the long run, students' quality and ability will be greatly improved.

\section{REFERENCES}

[1] Zhi Jianming, Zhang Wenhui, Zheng Yanqian. Application of student lecture in physiology teaching of " $4+4$ " clinical medicine major $\mathrm{J}$ basic medical education, 2018,20 (9): 722-724.

[2] Yabailiu, Cheng Hongju, Xin Qing, et al. Exploration of physiology teaching mode reform under the demand of medical innovative talents training $\mathbf{J}$ - medical education research and practice, 2018,26 (3): 384-386.

[3] Yu Boyang, Xue Mingming, application of Blended Teaching in physiological experiment $\mathbf{J}$. continued Medical education, 2018,9 (32): 62-63.

[4] Xie Wei. Problems in physiology experiment teaching and exploration of teaching reform in medical colleges and universities $\mathbf{J}$ - continuing medical education, 017,1 (2): 18-19.

[5] Song Yishan, Sheng Jie, Kang Yongfeng, et al. Discussion on the application of split class in organic chemistry experiment teaching $\mathbf{J}$ Guangdong chemical engineering, 016,8 (43): 172,82 .

[6] Liu Yuchun, Dou Guiping, Cheng Quan. Research on the application of "split classroom" teaching mode in Engineering Experimental Course -- Taking "signal and system" experimental course as an example J - Journal of Lanzhou Institute of education, 2016,32 (7): 97-99.

[7] Zhang Xuexin - "bisection classroom": a new exploration of university classroom teaching reform J. Fudan Education Forum, 2014,12 (5): 5-10.

[8] Chen Lanmei, She Ji, Li Xiaofeng, et al. Application of "split class" in experimental teaching of basic medical chemistry J - Guangzhou Chemical Engineering, 017,5 (13): 168 - 169.

[9] Bi Jianyun, Dong Xinmei, Zhanqi, et al. . exploration on the application of split class and PBL joint teaching method in pharmaceutical engineering practice teaching $\mathbf{J}$ - Shandong chemical industry, 017,6:83-84.

[10] P. Xu, J. Cao, et. al., Quantum chemical study on the adsorption of megazol drug on the pristine BC3 nanosheet, Supramolecular Chemistry, 33(2021)63-69.

[11] P. Xu, C. Geng, et. al., Application of Boron-doped Graphdiyne (BGDY) in Dehydrogenation of Benzyl Alcohol to Benzaldehyde, Basic \& Clinical Pharmacology \& Toxicology, 128SI3(2021)97-98. 